\title{
Commodity Approach to Materials When Manufacturing Containers for Food
}

\author{
Yakov G Verkhivker ${ }^{1 *}$, Ella I Altman², Natalya V Dotsenko² and Elena M Miroshnichenko ${ }^{2}$ \\ ${ }^{1}$ Doctor of Technical Sciences, Odessa National Academy of Food Technologies, Ukraine \\ ${ }^{2}$ Department of Food, Odessa National Academy of Food Technologies, Ukraine
}

Submitted: July 16, 2020; Published: August 17, 2020

*Corresponding author: Yakov G Verkhivker, Doctor of Technical Sciences, Odessa National Academy of Food Technologies, Ukraine

\begin{abstract}
Food safety is inextricably linked to the safety of containers and packaging. Glass, metal and polymer containers are the most traditional types of packaging used for packaging food products. Glass jars is the safest, chemically inert type of containers, since environmentally friendly materials are used for its manufacture, and when packing, storing food products, the material of such containers does not affect the quality and safety of the finished product. Metal containers are made in two fundamentally different stamping methods: a solid can and a prefabricated can, which consists of three parts (two bottoms and a body). From the ecological point of view, the greatest danger is posed by a prefabricated tin made of tin and a longitudinal seam, which is formed by the crypt method and subsequent soldering with a special solder consisting of lead and tin. In case of violation of the technology of production, use and storage of containers with a food product, the contents of the can directly contact with tin-lead solder. During storage, the content of lead and tin salts increases in the product, which reduces its environmental safety. Also problematic in the production of metal containers are paint and varnish coatings of metal, which can also be a source of migration of chemicals into food. Polymer containers are very relevant now for the manufacturer and the buyer, but polymer materials during the storage of food products also release chemicals, deteriorating the quality of the product and reducing its shelf life.
\end{abstract}

For the microbiological safety of food products, the thermophysical properties of the materials from which the container is made are of great importance, which is taken into account when developing the modes of heat treatment of food products, otherwise there will be microbiological defects in the finished product and food poisoning among its consumers.

Keywords: Materials; Manufacturing containers; Food; Packaging; Glass jars; Friendly materials; Storing food products; Quality; Safety; Environmental safety

\section{Introduction}

The main requirements for canned food containers are absolute tightness, chemical and mechanical resistance of the material from which it is made, resistance to high sterilization temperatures. A canned product in a sealed package can be stored for many years without deterioration. In addition, the cans should be easy to handle, suitable for effective washing and sanitization, and not be unnecessarily heavy. For the production of canned food, three types of containers are used - glass, metal and polymer.

\section{Glass Jars}

One of its advantages is its high resistance to the action of acids, salts, proteins and other substances, which makes it possible to produce any canned food in glass jars. In addition, glass jars are easy to sanitize and can be reused. The adopted shape of glass jars provides them with a relatively high thermal stability.
The disadvantages of glass jars include the relatively large weight of the cans themselves and significant instability to mechanical stress.

All amorphous bodies obtained by supercooling a melt are called glass. The main component of industrial glasses is silica. It is introduced into glass in the form of quartz sand, which is the main raw material in the glass industry. The quality of glass containers largely depends on the quality of quartz sand. High-grade quartz sands should contain 99-99.8\% silicon oxide $\mathrm{SiO}_{2}$ and 1-0.2\% impurities. The following substances are also introduced into the composition of sand:

- Boron oxide $\mathrm{B}_{2} \mathrm{O}_{3}$ - with boric acid, brown or browncontaining mineral-Asharite.

- Aluminum oxide $\mathrm{Al}_{2} \mathrm{O}_{3}$ - with clay impurities in sand, with clay, feldspar, as well as with pure Alumina. 
- $\quad$ Sodium oxide $\mathrm{Na}_{2} \mathrm{O}$ - with different types of soda products (soda ash, soda-potash mixture, sodium sulfate, etc.,).

- $\quad$ Calcium oxide $\mathrm{CaO}$ - with limestone, chalk.

The glass container production process consists of a set of operations aimed at obtaining molten glass, called glass mass, and operations aimed at forming glass jars from liquid glass mass and for their final finishing in the form of industrial products. Jars are made of colorless or semi-white glass in accordance with regulatory documents. It is allowed to make jars of soda-calciumsilicate colorless or semi-white glass of other compositions approved by the national health authorities for contact with food. The shape, main dimensions of cans and neck rims, full capacity must comply with the requirements of the regulatory document.

Violations of the technological regime and the rules of technical operation of the equipment can lead to defects in finished glass jars. Some of them are not allowed, while others are limited. The following defects are not allowed:

- $\quad$ Lack of penetration (glass inhomogeneity) and ruck (crystallized opaque glass particles).

- Open bubbles on the surface, collapsing when lightly tapped with a metal rod.

- Midges (small bubbles up to $0.8 \mathrm{~mm}$ in diameter, concentrated in one place) and others.

Banks must be thermally resistant with a temperature difference of at least $40^{\circ} \mathrm{C}$, withstand without destruction for $5 \mathrm{~s}$, the internal hydrostatic pressure of $0.25-0.3 \mathrm{MPa}$, withstand without destruction the compression force in the direction of the vertical axis of the body at least $3000 \mathrm{~N}$, must be acid resistant. On the outer surface of the cans, it is allowed to apply protective and hardening coatings approved by the national health authorities for contact with food products [1-3].

\section{Metal cans}

This type of container has a small mass compared to a food product, it is light and has a high thermal conductivity. Tin containers of the required dimensions can be manufactured at canneries. However, the tin container has a number of disadvantages. When storing canned food in tinplate containers, corrosion processes occur, that is, the transition of metal under the influence of the environment (air or food) into various oxide compounds or salts of organic acids. During storage in warehouses, especially unheated ones, the outer surface of the can begins to become covered with oxidation products (rust). This process takes place in spite of the tin layer covering the iron base of the tin, because the tin layer has pores. In autumn, spring, and for the south and in winter, during the day in warehouses, the air temperature changes sharply and at its high relative humidity conditions are created when the air saturated with water vapor cools when it comes into contact with canned food stacks (the temperature of canned food does not change as sharply like air), at the surface of the tin container, it is oversaturated with water vapor and moisture drops are deposited on the tin surface. In the droplets of moisture deposited on the contaminated surface of the tin, an electrical element iron-tin is formed, and the conductor is water contaminated with organic and inorganic compounds. Iron and tin have different electrical potentials. Under these conditions, iron dissolves, and tin is retained. The water dries up and the tin becomes covered with rusty spots.

When in contact with canned food containing organic acids, the electrical potential of tin changes depending on the $\mathrm{pH}$ of the canning medium, and the transition of tin into canned food begins. For this reason, health authorities have standardized the tin content of canned food. The maximum tin content in vegetables and other types of canned food should not exceed 200mg per $1 \mathrm{~kg}$. Coating the inner surface of the cans with varnish or enamel significantly reduces the transition of tin into canned food.

All metal cans used in the canning industry are divided into two main types.

- $\quad$ The first type is prefabricated cans, consisting of three parts: body, bottom and lid. The body of prefabricated cans is, as a rule, a cylinder formed by joining two opposite edges of a rectangular blank (body blank). For the final formation of the can, the bottom is rolled to one of the ends of the body, and the lid to the other (after filling with the product).

- $\quad$ The second type is two-piece (one-piece) cans, in which the body and bottom are a single seamless container, which, after filling with the product, is rolled up with a lid. Solid cans are made by various cold stamping methods (Figure 1).

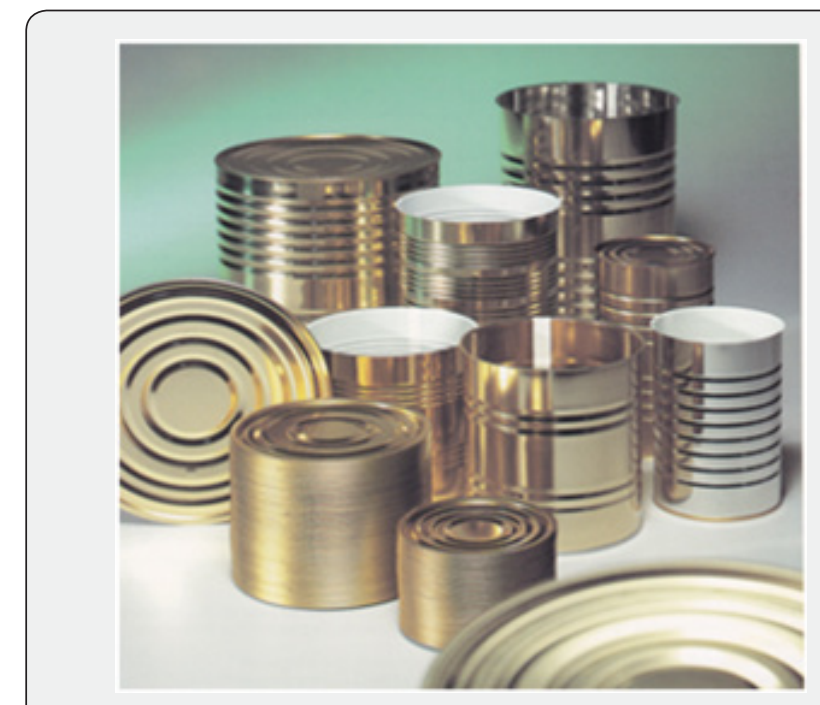

Figure 1: Metal Cans.

The use of tinplate for the manufacture of metal cans is primarily due to its higher corrosion resistance compared to black cold-rolled tinplate. The relative safety of tin in contact with food products has made it possible to widely use tinplate with a certain thickness of the protective tin coating. In addition to hot tin- 
plated sheet tin, used for the production of cans and lids for glass containers is white roll tin without varnish and varnished with the brand VHT (varnished hot tin) and VET (varnished electrolytic tin). Rolled white lacquered sheet should have a shiny surface without lacquer drips, bubbles, non-varnished areas. The color of the surface of the sheet must be uniform. Tinplate is available in various widths to reduce waste when making cans. To reduce the consumption of tin, rolled sheet metal of electrolytic (non-hot) tinning is produced. Tin consumption during electrolytic tinning is reduced by 2-3 times. The electrolytic tin plate is covered with a double layer of varnish. In addition to tinplate, rolled tin of the BLT brand (black lacquered tin) is produced, from which lids for glass containers are produced.

The most suitable material for the manufacture of stamped cans is aluminum. The advantages of aluminum containers in comparison with tin ones are higher thermal conductivity, better punching ability, lower weight and ease of opening. Aluminum is non-toxic and reflects light and heat well. Pure aluminum has insignificant strength, therefore, in the production of canned containers, its alloys with manganese and magnesium are used, despite their lower resistance to food products. The composition of aluminum alloys includes alloying elements that increase the properties of the alloy as a material for canning containers. Aluminized sheet is obtained by applying a layer of aluminum with a thickness of 1-5 microns on rolled steel strip. The metallization process is carried out in an atmosphere of high vacuum -0.13$0.013 \mathrm{~Pa}$. In this case, the atoms of the evaporated aluminum condense on the surface of the steel strip, the temperature of which is lower than the temperature of the evaporated aluminum. Aluminum alloys are produced in the form of sheets, which must be lacquered on both sides. The composition and number of varnish coats should be different for the inner and outer sides of the sheet. Aluminum tape is produced according to the range of food products. Thickness of aluminum tape - $0.25-0.39$, aluminum sheets $-0.3 \mathrm{~mm}$. The quality of aluminum sheets and strips is controlled in accordance with the requirements of regulatory documents.

It shows the uniformity, smoothness, color and gloss of the varnish coating, the absence of defects on the surface (delamination, cracks, bubbles, cavities, burn-out, non-varnished areas), the ability to withstand the corresponding tests for drawing and bending, deep stamping and the action of aggressive environments. Due to the ever-increasing price of tin, a search is being made for alternative materials used to make metal cans. The most successful developments in this direction are associated with the creation of a material where chromium is used as a protective coating instead of tin. The application of chromium, as in the case of tin, occurs electrolytically. The mass of chromium applied is less than $100 \mathrm{mg}$ per $1 \mathrm{~m}^{2}$, while the mass of tin applied is calculated in grams. With the electrolytic method of applying chromium on the surface of steel, layers are created consisting of metallic chromium and chromium oxide. Such a coating creates a passivation film with good adhesion to the steel base and paintwork material, which provides good protection against under-film corrosion (Figure 2).



Figure 2: Metal Cans Surrounded with Aluminum Sheet.

Unfortunately, chrome-plated tin without additional processing cannot be used in the manufacture of prefabricated cans with a soldered or welded longitudinal seam. It is also impossible to make deep-drawn cans from it with thinning. This material is most widely used in the manufacture of products only by stamping or drawing. For example, lids for metal and glass jars, crown caps, stamped jars, etc. The use of chromiumplated lacquered tin for the manufacture of cans is possible only in the absence of the transition of chromium into the product/ because chromium is one of the metals, the transition of which into the product should be limited. The maximum permissible concentration of chromium in water bodies for sanitary and 
domestic use is regulated within the $0,1 \mathrm{mg} / \mathrm{l}$ (for $\mathrm{Cr}^{6+}$ ) $-0.5 \mathrm{mg}$ / l $\left(\mathrm{Cr}^{3+}\right)$. Hexavalent chromium ions are considered particularly toxic. However, chromium, which dissolves in food products, is a salt of trivalent chromium, since hexavalent chromium compounds can only form in an environment where there are strong oxidants, high pressure and high temperature. Therefore, in canned food, where there are no substances that are oxidizing agents, and the pressure in cans during storage, as a rule, is below atmospheric, chromium can be found only in the $\mathrm{Cr}^{3+}$ form.

To combat corrosion, tin or other materials from which cans are made must be varnished. Paints and varnishes used to protect the inner and outer surfaces of metal cans must meet the following requirements:

- To form a coating resistant to the action of the components of the preserved product.

- Migration of metal ions from the base, as well as organic substances from paint and varnish coatings into the product should not exceed the values established by the standards.

- Have good adhesion to the metal base of the container.

- $\quad$ Have the ability to vary over a wide range of coating thickness during application.

- $\quad$ To form an almost non-porous varnish film with high scratch resistance.

- $\quad$ Be Quick drying.

- $\quad$ The lacquer coating must be resistant to sterilization temperatures.

- The lacquer coating must have good deep drawing ability (for solid cans) and maximum resistance to deformation.

- $\quad$ Ensure the absence of foreign taste in canned products.

Coatings made from materials based on a mixture of epoxy and phenol-formaldehyde resins are especially resistant to the action of food components. Welded longitudinal seams of prefabricated cans are covered with special seam varnishes, which are divided into liquid and powder. One- or two-component liquid joint varnishes are made on the basis of organic sols, epoxy, vinyl and acrylic resins, sometimes pigmented with aluminum. Partially find application of varnishes based on powder-suspension compositions. They are water-soluble or alcohol-soluble powder emulsions applied by roller or spray application. Powder varnishes, unlike liquid varnishes, are a material characterized by the absence of solvents in their composition, which ensures the possibility of short-term (from 3 to 10s) high-temperature drying and does not go against the requirements of sanitary and environmental safety of production. The properties and method of applying powder varnishes make it possible to obtain a varnish film of the required thickness, which makes it possible to exclude contact of the product with the surface of the weld [4]. Varnishes and enamels used for tin coating should not contain harmful impurities: salts of heavy metals, substances that give the product an off-taste, smell or color. Lacquer and enamel films must withstand mechanical and heat treatment, which is necessary for the manufacture of cans and during technological processes. The film should not peel off from the surface of the sheet metal, form cracks, but it should withstand, without changes, heating at a temperature of $121^{\circ} \mathrm{C}$.

The density and strength of the varnish film is checked by boiling samples of varnished tin for 2 hours in a 50\% solution of sugar, $3 \%$ sodium chloride, $12 \%$ tomato puree and $3 \%$ vinegar acid. The lacquer coatings should not be altered by such treatment. Tin, from which containers for canned food are made, containing many protein substances (crab, chicken), are covered with protein-resistant enamels. The enamel must withstand boiling for two hours in a $3 \%$ solution of sodium chloride or in a solution of $3 \%$ gelatin and $1 \%$ sodium chloride. The solution is saturated with hydrogen sulfide $\left(\mathrm{H}_{2} \mathrm{~S}\right)$. The composition of varnishes includes natural or synthetic organic resins (copal, etc.), oils (tung, linseed) and solvents (turpentine, spirit). Protein-resistant enamel is made of varnish with the addition of zinc oxide ( $\mathrm{ZnO}$ ). This is necessary because in the process of sterilization, protein compounds begin to break down under the influence of temperature, and in the process of decomposition sulfur compounds are released, which, reacting with the tin of the tin, give deposits on the surface of the tin (black and blue) of tin sulfide. If these protein breakdown products come into contact with the enamel film, which contains zinc oxide, then white zinc sulphide compounds will form on the surface of the film, and not black-brown deposits of tin sulphide. To obtain good (non-porous) coatings, the varnish is applied in two layers. The thickness of the coatings is 10-15 microns. The outer side of the can is sometimes lithographed. Drawings, printing, paints are applied on special machines. A can, the inner surface of which is coated with varnish, and the outer surface with lithography and varnish, is much less exposed to corrosion [1-5].

\section{Polymer Cans}

Polymers are among those new economical materials that in some cases can replace tin and glass in the production of canned containers. They are used for packaging food concentrates, dried fruits and vegetables and food products, canned by chemical and aseptic methods, and in combination with other materials can be used for hermetic packaging of pasteurized products-jams, preserves, etc. and even for the manufacture of containers filled with a product to be heat sterilized.

Polymer containers have a many of valuable technical properties, high aesthetic qualities and are becoming more widespread in the food industry. To a greater extent than to any other types of materials, special requirements are imposed on polymers in terms of mechanical strength, chemical resistance to the action of food components, economy, scarcity and low cost of raw materials in comparison with such materials. as metal 
and glass, as well as high manufacturability - the possibility of processing into finished products by high-performance methods with low labor costs, sanitary and hygienic impeccability, that is, the impossibility of passing into a food product from a polymer material of foreign substances that change taste and the smell of the product, as well as harmful to the human body. A number of specific ones are added to these general requirements: for polymer coatings - high adhesive resistance and impermeability; for polymer container and packaging materials-the highest possible degree of tightness (impermeability to microorganisms, as well as water, steam, gas and aroma tightness); low light transmission, especially for ultraviolet rays.

The main polymeric materials include the following:

- Lacquered cellophane, cellophane coated with a copolymer of vinylidene chloride and vinyl chloride or coated with vinylidene chloride and acrylonitrite.

- $\quad$ Polyolefins - polyethylene, polypropylene, copolymers of ethylene with propylene.

- Pliofilms - films based on rubber hydrochloride, for example, ekagshen (synthetic isoprene rubber hydrochloride with the addition of sorbic acid as a structuring).

- Polymers based on vinyl chloride (for example, suspension polyvinyl chloride with plasticizers, fillers, stabilizers and lubricants).

- Materials based on polystyrene (for example, polystyrene obtained by combining a copolymer of styrene and acrylonitrite with nitrile rubber).

- $\quad$ Polyamide packaging materials.

- $\quad$ Polyester films based on polyethylene terephthalate (for example, lavsan).

- $\quad$ Fluoroplastics, etc.

Most of the polymer packaging materials have a complex of valuable properties, but there is not one among them that would fully satisfy the above requirements. So, for example, cellophane is strong, transparent, low-permeable to gases, impeccable in sanitary and hygienic terms, but not resistant to moisture, difficult to heat-weld, has little aesthetic; polyethylene film has good water resistance, chemical resistance, low vapor permeability, easily amenable to thermal welding, however, it is oxygen-permeable, not strong enough, unstable to oils and fats; polyethylene terephthalate film is impeccable in sanitary and hygienic terms, transparent, durable, little gas, steam and water permeability, but it is difficult to heat seal; polyamide films have high strength, elasticity, heat resistance, insignificant gas permeability, but not sufficiently resistant to moisture, difficult to heat-seal, etc. Therefore, they try to make polymer containers and packaging from combined materials that combine the best properties of individual components. By selecting the required combination of single film components, it is possible to obtain a multilayer packaging material with virtually any desired properties. Especially widespread was the polyethylene-polyamide film.

Combined packaging materials are obtained not only from multilayer polymer films, but also from paper or cardboard with polymers or from aluminum foil with polymers, etc. Combined cellophane-polyethylene material is widespread in packaging technology, combining high mechanical strength and low gas permeability of cellophane with moisture resistance, elasticity and the ability to heat-seal polyethylene.

Packaging materials based on aluminum foil most reliably protect food from the external environment. Such materials have two main structures: polymer-aluminum foil - polymer and polymer-paper- aluminum foil-polymer. The outer layer of polymer protects the material from mechanical damage and from aggressive chemical factors. The inner layer of the material must ensure thermal welding, protect the surface of the aluminum foil from the action of the food product. Boxes and bags made of paper and cardboard with polymer coatings or inserts for frozen products are widely used in the food industry. Well, for example, apple, grape, tomato, cherry, blackcurrant and other juices packaged in bags made of combined materials: cellophanepolyethylene, polyethylene-coated paper, cellophane, retain their quality. aluminum foil - polyethylene.

Paste-like non-pasteurize types of food products: jam, marmalade, confiture, mashed apples with sugar, the safety of which is ensured by a high concentration of osmotically active substances, it is advisable to pack in small polymer containers. on renewal of polyvinylchloride or polystyrene (jars, cups, boxes). Liquid food products, the stability of the quality of which during storage is based on aseptic filling or on the addition of preservatives, are currently packed in paper or cardboard containers with polymeric coatings (rectangular or tetrahedral) similar to those used for packaging long-term storage milk. Such a container consists of several layers of materials according to the scheme lacquer (or paraffin)-paper-aluminum foil - polyethylene. These products are also packaged in polymer bottles. For the manufacture of canned food, the safety of which must be ensured by heat sterilization, use polymer containers based on polyethylene terephthalate - polyethylene, polypropylene, polyamide and other heat-resistant polymer materials, with special attention paid to the strength of the welded seams and measures to maximize the removal of air from the container when packing in order to prevent the occurrence of excessive pressure during sterilization. The pressure in the apparatus during the entire cycle must exceed the pressure in the container, preventing the bags from blowing. It is also possible to sterilize canned food in containers made of rigid polymeric materials (for example, glasses) based on polyethylene or high-density polypropylene, sealed with tin lids. 
Polymeric packaging materials have been used for long-term storage of fruits and vegetables, the stability of which is ensured by the creation of a modified atmosphere. By selecting polymers by type, film thickness and selective gas permeability, in a number of cases, it is possible to achieve optimal conditions for gas exchange and environment, which ensure long-term storage of fruits and vegetables. Small packaging $(0.5-1 \mathrm{~kg})$ - bags made of polymeric materials - for economic reasons are used mainly for citrus fruits, pears, berries, and for cheaper fruits and vegetables, large packages (boxes, chambers) with polymer inserts and -wings. For the constancy of the composition of the gas mixture inside the polymer packing, its permeability to oxygen and carbon dioxide is of decisive importance [6-11]. The sterilization process is the main technological operation in the canned food production technology, where we obtain food products for long-term storage.

Different types of material in cans have different thermal and physical properties that affect the heating time of the packaged product in cans, when developing modes of heat treatment of cans. Sterilization time $\tau$ ster is one of the main microbiological parameters of heat treatment, which affects the microbiological stability of canned food during storage, ensuring industrial sterility of the product, the absence of microbiological defects in products and food poisoning. This parameter is fixed in the sterilization formula for a certain type of product and container and is approved in the technological instruction. The sterilization time tster consists of two components - the time it takes to destroy microorganisms in the center of the sealed container with the product (at the point of the worst heating), it is called lethal or lethal $\tau_{1}$ (this is a microbiological component) and the time it takes to warm up the container with the product or time reaching the sterilization temperature in the center of the can $\tau_{2}$ (this is the thermophysical component of the sterilization time):

$$
\tau_{\text {ster }}=\tau_{1}+\tau_{2}
$$

Before heating the product, the heat must overcome the thermal resistance of the material itself, the thickness of the container wall $\sigma$, which depends on the ratio of the wall thickness and its thermal conductivity: the greater the thickness of the can and the lower its thermal conductivity, the greater its resistance. The wall thickness of the metal container is very small $\delta=0.0002$ $0.0003 \mathrm{~m}$, the thermal conductivity of the metal is large and equal to $\lambda=47-52 \mathrm{~W} /\left(\mathrm{m}^{*} \mathrm{~K}\right)$ and the thermal resistance of such a can is, on average,

$$
\sigma=\delta / \lambda=0.5 * 10-5 K / W
$$

This is a small value and it is not affected by fluctuations in the wall thickness of the metal container and cannot significantly affect the thermal resistance of the can wall.

The wall thickness of the glass container is 10 times greater than the thickness of the metal container and is equal to $\delta=0.002-0.006 \mathrm{~m}$, the thermal conductivity of the glass is low of the order of $\lambda=0.6-0.9 \mathrm{~W} /(\mathrm{m} * \mathrm{~K})$, i.e. $80-90$ times less than the thermal conductivity of tin and the thermal resistance of glass is significantly $\sigma=\delta / \lambda=0.01 \mathrm{~K} / \mathrm{W}$ and significantly changes from fluctuations in the thickness of the container wall. If we take $\sigma$ for metal containers as 1 , then $\sigma$ for glass containers will be 1000 such units. Consequently, fluctuations in the wall thickness of a glass container can have a very significant effect on its thermal resistance. And it is very important in the production of glass canning containers to control this quality indicator of cans for compliance with the requirements of the current regulatory document and it is imperative to control these values during the incoming inspection of glass containers at canning factories, because the effectiveness of heating the microbiological stability of the canned product depends on it.

Polymer packaging made of polyethylene terephthalate has a thermal conductivity $\lambda=0.14 \mathrm{~W} /\left(\mathrm{m}^{*} \mathrm{~K}\right), \delta=0.0001 \mathrm{~m}$, not less, then $\sigma=\delta / \lambda=0.0007 \mathrm{~K} / \mathrm{W}$ semi-rigid polymer packaging lamister, which is made from a combined sterilizable material based on aluminum foil and polypropylene, has higher thermophysical properties compared to PET containers. The thermal resistance of the container wall is of interest to us only in combination with the time of penetration of heat into the depth of the product during sterilization of canned food.

In practice, there are options:

i. Sterilization of a liquid product in a metal container, when heat transfer proceeds convectively from the coolant to the container wall (heat transfer coefficient $\alpha_{1}$ ), then heat is transferred by heat conduction through the container wall and then convectively goes from the container wall to the product (heat transfer coefficient $\alpha_{2}$ )

$$
\sigma=1 / \alpha_{1}+\delta / \lambda+1 / \alpha_{2}
$$

Calculations have shown that the values $1 / \alpha_{1}$ and $1 / \alpha_{2}$ are small, the thermal resistance of such a system has an even lower value, therefore the thermal resistances are distributed in a ratio of 100:1:100.

ii. Sterilization of a liquid product such as juices, drinks, fruit and vegetable puree in glass containers has a thermal resistance ratio of 100:1000:100; the heating time of such a container is several times longer than in the previous version (here a total of 1200 units) and the time of heating a liquid product in glass containers is mainly influenced by the material of the cans.

iii. Sterilization of a thick product such as tomato paste, pate in a metal container, its heating proceeds according to the scheme - from the heat carrier to the container convectively $\left(\alpha_{1}\right)$, then conductively through the container wall $(\delta / \lambda)$ and thick product $\left(\delta_{\mathrm{pr}} / \lambda_{\mathrm{pr}}\right)$, thermal resistance

$$
\sigma=1 / \alpha_{1}+\delta / \lambda+\delta_{p r}+\lambda_{p r}
$$

Since the thickness of the product wall is several hundred 
times greater than the thickness of the metal wall, and $\lambda$ pr (about 100 times) is less than $\lambda$ still, it has a thermal resistance ratio of 100: 1: 25000 , the heating time of such a can is longer than the heating time of the container with the product, where heating is convective and the heating time is influenced exclusively by the physical properties of the product.

iv. When sterilizing a thick product in a glass container, the ratio of thermal resistances for this system is 100: 1000: 25000 and the time of penetration of heat into the center of such a container is long and is determined exclusively by thermal resistance, the consistency of the product, since in comparison with it the share packaging is $4 \%$.

Polymer containers occupy an intermediate position in terms of thermal properties between glass and metal containers. The thermal resistance of containers when developing modes of thermal sterilization of products is important only in conjunction with how it affects the time of heat penetration to the point of the worst heating of the product. Depending on the type of product - convectively or conductively heated, heating occurs in different ways. Therefore, the consistency of the product must be taken into account - liquid (juices, mashed potatoes) and thick (jam, tomato paste, pates) $[7,10,12]$. The issues discussed in this article are relevant in the technology for the production of canned food, as thanks to this, manufacturers produce high-quality and safe canned food $[13,14]$.

\section{References}

1. Verkhivker Ya G, Miroshnichenko OM (2018) The use of various types of consumer packaging in food production technologies. Packaging, 4: 1-8.

2. https://studfile.net/preview/8107594/page:6/

3. Yakov G Verkhivker, Elena M Miroshnichenko, Ella I Altman, Natalya V Dotsenko (2020) Using of Various Types of Consumer Containers in Technologies of Food Production. Journal of Diabetes and Endocrinology Research 1(1): 1-9.
4. http://www.vniitek.ru/rus_/page_ch286/view.html

5. http://www.comodity.ru/konserv/tarakonserv/1.html

6. https://alternativa-sar.ru/tehnologu/pishchevye-dobavkii-ingredienty/flaumenbaum-b-l-osnovy-konservirovaniyapishchevykh-produktov/2257-glava-iv-tara-dlya-konserv

7. Verkhivker Ya G, Ye. M. Miroshnychenko (2020) Canning food in semi-rigid polymeric and composite containers. Food Science and Technology ONAFT, 2: 111-119.

8. Verkhivker Ya G, Miroshnichenko EM (2016) Development of canning parameters for tomato-matny sauces and ketchups in polymer containers. Electronic scientific journal «Archivarius» (RINI), 10: 5660.

9. Yakov Verkhivker, Elena Miroshnichenko, Ella Altman (2018) Contemporary Types of Consumer Packaging and Food Packaging. International Journal of Bioprocess \& Biotechnological Advancements IJBBA 4(1): 109-113.

10. Verkhivker Y, Myroshnichenko E (2019) Development of technological parameters for food production in pet polymer tare. Journal of Materials Science and Nanotechnology 1(3)1-2.

11. Verkhivker Y, Miroshnychenko O (2020) Use of polymer consumer containers for preservations of food stuffs by heat sterilization. Monograph-Relevant Issues of the Development of Science 1(1): 1-4.

12. Verkhivker Ya G, Myroshnichenko OM (2019) Influence of thermophysical properties of canned food and food products on the parameters of the sterilization process. Thermophysics and thermal energy of ITTF NAS of Ukraine 41(3): 67-72.

13. Yakov Verkhivker, Elena Myroshnichenko (2019) The use of polymeric types of packaging technology food production. World Congress on Food Science and Technology, pp. 15-17.

14. Yakov G Verkhivker, Elena M Miroshnichenko, Ella I Altman, Natalya V Dotsenko (2020) Polymeric Consumer Containers PET (polyethylene terephthalate) In Food Production Technologies. International Journal of Innovative Studies in Sciences and Engineering Technology 6(5): 5355.

\begin{tabular}{l} 
Your next submission with JuniperPublishers \\
will reach you the below assets \\
- Quality Editorial service \\
- Swift Peer Review \\
- Reprints availability \\
- E-prints Service \\
- Manuscript Podcast for convenient understanding \\
- Global attainment for your research \\
- Manuscript accessibility in different formats \\
( Pdf, E-pub, Full Text, Audio) \\
- Unceasing customer service \\
Track the below URL for one-step submission \\
https://juniperpublishers.com/submit-manuscript.php \\
\hline
\end{tabular}

